\title{
Home Visitation Screening for Child Abuse Assessment in Korea
}

\author{
Hee-Soon Kim ${ }^{1}$, Tae-Im Kim² , Young-Hee Ju ${ }^{3}$, Ji-Young Lim ${ }^{4}$, Young-Ok Ha ${ }^{5}$, Ha-na Yoo ${ }^{6}$ \\ ${ }^{1}$ The Nursing Policy Research Institute, Department of Family Health Care, College of Nursing, Yonsei University, Seoul \\ ${ }^{2}$ Department of Nursing, College of Oriental Medicine, Daejeon University, Daejeon \\ ${ }^{3}$ Department of Nursing, Kimcheon Science College, Gimcheon \\ ${ }^{4}$ College of Nursing, CHA University, Seongnam \\ ${ }^{5}$ Department of Nursing, Kyungin Women's College, Incheon \\ ${ }^{6}$ Department of Nursing, Korean Bible University, Seoul, Korea
}

Purpose: The purpose of this study was to facilitate home visits to assess the current rate of child abuse in order to provide an agenda for the early detection and prevention of child abuse and neglect in Korea. Methods: For this retrospective descriptive research, 20 public health centers were selected, 1,991 families were visited and 2,680 children were assessed. Results: We found 415 cases (15.5\%) of potential abuse and 7 cases $(0.3 \%)$ of actual abuse. The greatest risk group was to children age 4 to 6 years. According to the HOME Inventory, there were 17 infants (5.8\%) presenting a potential risk for child abuse and neglect. Conclusion: Visitation screening is highly recommended for prevention in the high-risk preschool age group.

Key words: Child abuse, House calls, Nursing assessment, Early detection

\section{INTRODUCTION}

Child rights and protection are becoming increasingly important social issues in Korea. Increased interest in these issues may be due to a lower birth rate and the tendency of the current population of Korea to have fewer children than previous generations. Moreover, extended family functions and the support system of the family are becoming weaker as the influence of the nuclear family model increases. A high divorce rate and an economic crisis are associated with the increased likelihood of family dissolution, which may lead to increased rates of child abuse and neglect.

The main causes of child neglect are a changed child-rearing environment and increased poverty. These factors have resulted from an increase in 2-working-parent households and a changing socio-economic structure (National Child Protection Agency [NCPA], 2007). There is an association between child neglect and poverty, which suggests a need for family support targeted at high-risk groups with low levels of income and resources. It has been shown that a child protection system that facilitates the available networks of welfare and healthcare resources into a unified service system are needed for the detection and treatment of child abuse and neglect.

Screening for risk is essential in the prevention of child abuse and neglect. Though some clinicians suggest that prevention intervention should be primary by targeting the total population of families (Caldwell, Bogat, \& Davidson, 1988), the current trend toward a reduction in funding for social programs requires that resources be focused on families at the greatest risk. Screening enables us to identify and target interventions toward children and families at risk (Murry, Baker, \& Lewin, 2000). A number of countries in the world have statutory government-sponsored homevisitation schemes, usually using health professionals such as community nurses. Most of these schemes were set up with the aim of preventing ill health in families with young children and reducing the rates of morbidity and mortality in young children. Community nursing services such as 'health visiting' could be used to prevent child abuse and neglect at a primary and secondary level (Browne, 1995).

주요어: 아동학대, 가정방문, 간호사정, 조기발견

Address reprint requests to: Ha-na Yoo

Department of Nursing, Korean Bible University, Dongil-ro (st) 214-gil 32, Nowon-gu, Seoul 139-791, Korea

Tel: +82-2-950-5501 Fax: +82-2-950-5408 E-mail: hanay@bible.ac.kr

투고일: 2012년 3월 23일 / 1차수정: 2012년 6월 26일 / 2차수정: 2012년 7월 9일 / 게재확정일: 2012년 7월 15일 
The reported cases of child abuse increased rapidly in South Korea from 2,606 cases in 2001 to 7,083 cases in 2007 (NCPA, 2010). In response, the Korean government revised the Child Welfare Law in 2000, enacted the Law for Missing Children in 2005, established 17 protection centers and increased the number of child protection agencies to 42 in 2006 in an attempt to manage this problem.

However, these efforts are limited to passive procedures for dealing with the sequelae of child abuse rather than to work toward its prevention. There are currently limitations to the protection of children's rights and welfare in Korea because there is no system for preventing and detecting child abuse. Unfortunately, over 80 percent of abused children were mistreated by biological parents and 77.5 percent of these children lived together (NCPA, 2010).

Several theoretical orientations indicate the potential beneficial effects of home visitation on violence and other outcomes. Human ecology theory (Brooten et al., 1986) clarifies the importance of the social environment-including not only the influence of parents, but also of social networks, neighborhoods, communities, and cultures-in child development. Evidence shows that an environment of community disorganization and poverty can be a source of crime and violence (Caruso Whitney, 1997). Home visitation is seen as strengthening the capacities of parents in successfully relating to their social environment and gaining access to social resources. Because the effects of parenting are critical in the development and prevention of child violence (Caruso Whitney, 1997), home visitors also teach effective parenting and work to strengthen the support of family members and friends (Bilukha et al., 2005). Although there is insufficient evidence to recommend a parent education and support program to prevent child maltreatment, home visitation programs have been shown to be effective in reducing abuse in high-risk families (McDonald, 2007). This means that the best way to prevent and detect this problem must involve home visitations. A family-centered approach is required to treat abusing parents.

Child abuse also results in significant developmental delays in infants and toddlers (Helfer, 1987), and children who experience child abuse or neglect are more likely to engage in social and physical risk behaviors such as early, unprotected sexual activity or alcohol and drug use (Mullen, Martin, Anderson, Romans, \& Herbison, 1996; Murry, Baker, \& Lewin, 2000). In two reviews published past year, a history of maltreatment is associated with deficits in numerous indices of adaptation across the lifecycle, in- cluding disturbances in attachment relations in infancy, deficits in frustration tolerance in toddlerhood, problems with self-esteem and peer relations in later childhood, and reduced educational and vocational attainment in adulthood. Victims of child maltreatment are also more likely to be involved in intimate partner violence, experience teen parenthood, and have difficulties parenting their children. Child maltreatment is also a nonspecific risk factor for multiple forms of psychopathology (Briere \& Jordan, 2009; Perepletchikova \& Kaufman, 2010; Weich, Patterson, Shaw, \& Stewart-Brown, 2009). Child abuse must be detected early in order to minimize its negative effects. This is a crucial issue which must be solved, and it should be a top priority of both the community and government. A government system is desperately needed to manage this problem.

The purpose of this study was to facilitate home visits to assess the current rate of child abuse in order to provide an agenda for the early detection and prevention of child abuse and neglect.

\section{METHODS}

\section{Design and sample}

This study was a retrospective descriptive research design to determine the actual rate of child abuse and to allow for early detection through a system of home-visiting nurses.

Twenty local public health centers in nationwide were selected and informed consent was obtained. The nurses visited families at high-risk of committing child abuse, including families on government support for basic needs or medical aid, single-parent families and families with children aged $<12$ years who were receiving free meals in school.

\section{Measurements}

The Screening Scale for Child Abuse (SSCA) was completed for all children by visiting nurses. Also, the children's heights and weights were measured on a standard scale. On the basis of the 2007 Child and Adolescent Standard Growth Charts in Korea (Centers for Disease Control \& Korean Academy of Pediatrics [CDC \& KAP], 2007), the measurements were divided according to age and sex. Children were classified as normal when they were between the 3rd and 97th percentile and abnormal when they were under the 3 rd percentile and over the 97th percentile.

Additionally, in children aged $<3$ years, the home environment and interactions with family members were assessed by visiting nurses using the Home Observation and Measurement of the En- 
vironment (HOME), and head circumference was measured with a non-elastic measuring tape by placing the tape around their head above the eyebrows and around the middle of the occipital prominence. The non-elastic tape was fitted to their head, and any hair pins or other accessories were removed before the procedure. On the basis of the 2007 Child and Adolescent Standard Growth Charts (CDC \& KAP, 2007), head circumference was also classified as normal when it was between 3 and 97 percentile and abnormal when it was under the 3rd percentile and over the 97th percentile.

\section{Screening scale for child abuse}

The SSCA was developed by 4 experts who consisted of the nursing school faculty member, especially pediatric health nursing and community health nursing, and a child abuse expert in the community. This scale was designed for use in children aged $<12$ years and consisted of 20 screening points. Cases were evaluated according to the total score, which was determined by summing each of the 'Yes' responses. Scores ranging from 0 to 3 were labeled as general cases, 4 to 7 as potential risk cases, and scores greater than 8 as cases of abuse. Cases responding 'Yes' to certain items (There are obvious signs of physical damage which suspected physical abuse; There are suspicious signs of sexual abuse; Do not attend school in spite of school age; Guardian has a mental illness; Parents think that my child messed up my life) were labeled as potential risk cases regardless of the total score.

Reliability analysis using a Cronbach alpha was used to test for the internal consistency of items. In this sample, the Cronbach's alpha for the entire instrument was .65 .

\section{Infant/Toddler HOME Inventory}

The infant/toddler version of the HOME scale (Caldwell \& Bradley, 1984) is administered in the child's home at a time when the child is awake and can be observed in interaction with the mother or another primary caregiver. During this visit of approximately 1 hr, the home visitor completes the 45-item HOME checklist. All items are scored in a binary (Yes-No) fashion. About twothirds of the items are based upon observation by visiting nurses; the remainders are based upon parental report.

Domains included responsiveness (11 items), acceptance (8 items), organization ( 6 items), learning materials ( 9 items), involvement (6 items) and variety (5 items). Each domain was evaluated according to the total number of 'Yes' responses in each domain. Total score ranged 0 to 45 : scores of 0 to 25 represented the lower half, scores of 26 to 36 the middle quartile, and scores of 37 to 45 the upper quartile. Higher score indicates better home environment and interactions with family members.

The interrater reliability for the original study was 90\%. The Uder-Richardson-20 coefficients (KR-20) for the original instrument was .89 (Elardo \& Bradley, 1981).

\section{Ethical concerns}

As an evaluation of a public health program using internal databases by a legally empowered governmental authority for the development of public health recommendations, no institutional review board approval was obtained. However, researchers have gotten verbal approval from director of twenty public health centers and home-visiting nurses. Secondly, before beginning the study, approved participants were explained that they can drop out of the research if they do not want to. They were also explained that it is anonymous so there is no possible disadvantage and process of study is ethical. Thirdly, data collections for kids were permitted by parents or guardians.

\section{Data collection and analysis}

Data were collected between April 16 and October 31 of 2006. Of 2,078 families meeting the criteria, 1,991 (95.8\%) were visited, and 2,680 children were assessed. Questionnaires and assessment tools were prepared in advance and distributed to the trained visiting nurses. The data was analyzed using SPSS version 15.0 for Windows (SPSS Inc, Chicago, IL, USA).

\section{RESULTS}

\section{Characteristics of participants}

Based on the data from 20 public health centers, 2,680 children were registered and assessed. In this study, 1,365 boys (50.9\%) and 1,315 girls (49.1\%) were sampled. Two hundred ninety-two (10.9\%) of the children in the study were aged $<3$ years, 565 (21.1\%) were aged 4 to 6 years, 889 (33.2\%) were aged 7 to 9 years, and 934 (34.8\%) were aged 10 to 12 years. The number of children with families on government support for basic needs was $1,836(68.5 \%)$, that of children with families on medical aid from the government was 356 (13.3\%), that of children with a single parent 362 (13.5\%), that of children with free school meals 115 (4.3\%), and that of cases which did not meet any of the above criteria $11(0.4 \%)$ (Table 1$)$.

Visiting nurses assessed the physical development status of 
Table 1. Characteristics of Participants

$(N=2,680)$

\begin{tabular}{lrr}
\hline Characteristics & $\mathrm{n}$ & $\%$ \\
\hline Socio-demographic variables & & \\
Gender & & \\
Boys & 1,365 & 50.9 \\
Girls & 1,315 & 49.1 \\
Age (year) & & \\
0-3 & 292 & 10.9 \\
4-6 & 565 & 21.1 \\
$7-9$ & 889 & 33.2 \\
10-12 & 934 & 34.8 \\
Vulnerable households & & \\
Families on government support for basic needs & 1,836 & 68.5 \\
Families on government support for medical aid & 356 & 13.3 \\
Single-parent families & 362 & 13.5 \\
Children receiving free school meals & 115 & 4.3 \\
Others & 11 & 0.4 \\
Physical development status & & \\
Percentile rank of height & & \\
$\quad$ Normal & 2,124 & 79.3 \\
Abnormal & 263 & 9.8 \\
$\quad$ Not measured & 293 & 10.9 \\
Percentile rank of weight & & \\
Normal & \\
Abnormal & 2,142 & 79.9 \\
Not measured & 486 & 18.1 \\
Percentile rank of head circumference* & 52 & 2.0 \\
Normal & & \\
Abnormal & 206 & 70.6 \\
Not measured & 21.2 \\
\hline
\end{tabular}

*Infants aged <36 months $(\mathrm{n}=292)$ were assessed.

each child. Height was measured for 2,387 (89.1\%) of all 2,680 children, and body weight was checked for 2,628 (98.0\%). Head circumference was measured in 230 (78.8\%) of the 292 children aged $<36$ months. In height, 2,124 children (79.3\%) were in the normal range of the 3rd to 97th percentile, and 263 children (9.8\%) were in the abnormal range of $<$ the 3rd or $>97$ th percentile. In weight, 2,142 children (79.9\%) were in the normal range of the 3rd to 97th percentile, and 486 children (18.1\%) were in the abnormal range of $<$ the 3rd or $>97$ th percentile. Head circumference was measured for 230 children who were aged $<36$ months. According to the percentile rank, 206 children (70.6\%) were in the normal range and 24 children (8.2\%) were in the abnormal range of $<3$ or $>97$ (Table 1 ).

\section{SSCA results by age}

According to the SSCA, there were 2,258 general cases, 415 potential risk cases and 7 abuse cases. Of the children aged $<3$ years, 244 (83.6\%) were general cases, 47 (16.1\%) were potential risk cases, and one (0.3\%) was an abused case. Of the children aged 4 to 6 years, $469(83.0 \%)$ were general cases, 95 (16.8\%) were
Table 2. SSCA Results by Age

$(N=2,680)$

\begin{tabular}{|c|c|c|c|c|}
\hline \multirow[b]{2}{*}{$\begin{array}{l}\text { Age } \\
\text { (year) }\end{array}$} & \multicolumn{3}{|c|}{ Results } & \multirow[b]{2}{*}{$\begin{array}{l}\text { Total } \\
\mathrm{n}(\%)\end{array}$} \\
\hline & $\begin{array}{c}\text { General } \\
\text { (less than } 4 \text { points) } \\
\mathrm{n}(\%)\end{array}$ & $\begin{array}{c}\text { Potential risk } \\
\text { (4 to } 7 \text { points) } \\
n(\%)\end{array}$ & $\begin{array}{c}\text { Abused } \\
\text { (more than } 8 \text { points) } \\
n(\%)\end{array}$ & \\
\hline $0-3$ & $244(83.6)$ & $47(16.1)$ & $1(0.3)$ & $292(100.0)$ \\
\hline $4-6$ & 469 (83.0) & 95 (16.8) & $1(0.2)$ & $565(100.0)$ \\
\hline 7-9 & $750(84.4)$ & 137 (15.4) & $2(0.2)$ & $889(100.0)$ \\
\hline $10-12$ & 795 (85.1) & 136 (14.6) & $3(0.3)$ & 934 (100.0) \\
\hline Total & 2,258 (84.2) & 415 (15.5) & $7(0.3)$ & $2,680(100.0)$ \\
\hline
\end{tabular}

SSCA= screening scale for child abuse.

Table 3. Results Assessed by Infant/Toddler HOME Inventory ( $N=292)$

\begin{tabular}{lcr}
\hline Category (score range) & $\mathrm{n}$ & $\%$ \\
\hline Upper (37-45) & 94 & 32.2 \\
Middle fourth (26-36) & 89 & 30.5 \\
Lowest half (0-25) & 17 & 5.8 \\
Not assessed & 92 & 31.5 \\
\hline
\end{tabular}

$\mathrm{HOME}=$ home observation and measurement of the environment.

potential risk cases, and $1(0.2 \%)$ was an abused case. Of the children aged 7 to 9 years, 750 (84.4\%) were general cases, 137 (15.4\%) were potential risk cases, and $2(0.2 \%)$ were abused cases. Of the children aged 10 to 12 years, 795 (85.1\%) were general cases, 136 (14.6\%) were potential risk cases, and $3(0.3 \%)$ were abused cases (Table 2).

\section{Results assessed by Infants/Toddlers HOME Inventory}

In infants aged $<36$ months according to the HOME Inventory, home environment and interactions with family members were assessed based on the visiting nurses' observations and the reports that their primary caregiver made. There were 17 infants in the 'lower half ( $<25$ scores)' category, suggesting a potential risk for child abuse and neglect (Table 3).

\section{DISCUSSION}

In this study, we investigated 20 public health centers and examed the at-risk family from birth to the age of 12 years. The present status of the Korean child protections system is assessed, and alternative strategies are proposed based on the results of this study.

According to the study, there were only 7 cases of abuse, which was insignificant. However, these cases should not be ignored or underestimated because it is well established that experiences during the early stages of life affect lifelong development. For many children, especially infants aged $<3$ years, abuse can be 
life-threatening. Actually, the National Report on Child Abuse and Neglect performed by the Ministry of Health and Welfare in 2009 (NCPA, 2010) indicated that 8 abused children were killed, 4 of whom were aged $<1$ year and 2 were aged between 4 and 6 years. Therefore, it is thought that the protection of children against abuse in these age groups requires regular visitation and screening. Since it is highly possible that children with potential risk reported by visiting nurses could be actual abuse cases, visitation screening is highly recommended for preventing child abuse in children.

After this work, both abuse cases and potential risk cases were reported and actions were taken by local authorities. Based on our results, it is suggested that continuous management by visitation screening can be effectively coordinated using home visits and a unified system for public health and welfare. Previous research on the Nurse Family Partnership (NFP) has shown nurse home visitation to be an effective means for reducing high-risk children's overall number of maltreatment reports (Olds et al., 1997). In addition Zielinski, Eckenrode and Olds (2009) provide new evidence that the nurse home visitation intervention had an effect on the onset of maltreatment.

To do this, first, nurses visit the families regularly in order to screen for abused children and potential risk and to assess their need and safety accurately. Second, local social welfare policies should cooperate with visiting nurses, and thus a multidisciplinary approach to the problem of child abuse can be created through a systematic policy.

Height, weight and head circumference are important markers of child development and are helpful in the detection or diagnosis of diseases, such as microcephaly or hydrocephalus, especially during the first several years after birth. With respect to physical development, of the children analyzed, 23.3\% had an abnormal height to weight ratio with $9.8 \%$ of them having abnormal height and $18.1 \%$ having abnormal body weight. This result suggests that children aged $<12$ years should manage their body weight through more aggressive interventions, such as parent education, nutrition monitoring and consultation with a dietician. The $8.2 \%$ of children aged $<3$ years fell within the abnormal range for head circumference. Head circumference has been linked to brain development and has been used as measures of cognitive development and academic achievement (Gale, O'Callaghan, Godfrey, Law, \& Martyn, 2004; Ivanovic et al., 2004). Both height and weight have been similarly linked to cognitive development (Karp, Martin, Sewell, Manni, \& Heller, 1992). Therefore, these markers must be measured regularly to detect developmental problems or diseases. It is suggested that not only physical developmental delay but also overall development evaluation should be confirmed early in preschoolers by reliable measurements such as the Denver Developmental Screening Test (DDST), though simple physical measurements were made in this study.

Child abuse results from complicated and unpredictable interactions of personal, familial and social risk factors. It is important to address child maltreatment with specialized organizations for child protection, because the child and family have various problems and needs (Park, 2002). Therefore, a systematic and unified service system connecting and facilitating the various organizations in the community must be implemented (Hong \& Kim, 2007). A great deal of time, money and resources are required to correct child abuse once it has already happened, but the positive effects of these types of interventions are limited. Therefore, a system must be established to prevent child maltreatment and to detect it at earlier stages. A continuous and systematic approach, including networking, is needed for the lifetime management of child protection. Pregnant women should be registered prior to delivery and after birth and public care for children should be provided thereafter. Preschool children must be protected and managed by the community, and school-aged children must be assessed by their school and daycare centers.

Barriers to implementing home visitations frequently discussed in the literature include difficult in the retention of program staff. Home visiting personnel (especially when paraprofessional lay visitors are used) may be hard to recruit, train, and retain due to low pay and difficult work conditions. It has also been noted that paraprofessional visitors may require more training and supervision than nurses (Bilukha et al., 2005).

\section{CONCLUSION}

In conclusion, visiting nurses will contribute to the accessibility of these assessment services to the families in the community by building relationships and bonding with children and their family members. Through these interactions, visiting nurses can prevent the occurrence of child abuse. Furthermore, visiting nurses will determine whether the family is at risk for child maltreatment, which will minimize or prevent abuse and reduce the health costs for the child abuse. Harmonious interactions and clear role descriptions are essential for individuals working in the health and welfare system in order to provide continuous, systematic and 
qualitative services. Community healthcare nurses and a budget for prevention of child abuse should be prior to facilitating the house calls system.

\section{REFERENCES}

Bilukha, O., Hahn, R. A., Crosby, A., Fullilove, M. T., Liberman, A., Moscicki, E., et al. (2005). The effectiveness of early childhood home visitation in preventing violence. American Journal of Preventive Medicine, 28, 1139.

Briere, J., \& Jordan, C. E. (2009). Childhood maltreatment, intervening variables, and adult psychological difficulties in women: An overview. Trauma Violence Abuse, 10, 375-388.

Brooten, D., Kumar, S., Brown, L. P., Butts, P., Finkler, S. A., Bakewell-Sachs, S., et al. (1986). A randomized clinical trial of early hospital discharge and home follow-up of very-low-birth-weight infants. The New England Journal of Medicine, 315, 934-939.

Browne, K. (1995). Preventing child maltreatment through community nursing. Journal of Advanced Nursing, 21, 57-63.

Caldwell, B. M., \& Bradley, R. H. (1984). Manual of Home Observation for Measurement of the Environment (Rev. Ed.). Little Rock: University of Arkansas Press.

Caldwell, R., Bogat, G., \& Davidson, W. (1988). The assessment of child abuse potential and the prevention of child abuse and neglect: A policy analysis. American Journal of Community Psychology, 16, 609-624.

Caruso Whitney, G. A. (1997). Early intervention for high-risk families: Reflecting on a 20-year-old model. In: G. W. Albee \& T. P. Gullotta (Eds.), Primary prevention works. Thousand Oaks, CA: Sage.

Centers for Disease Control, \& Korean Academy of Pediatrics (2007). 2007 Child and Adolescent Standard Growth Charts. KOREA Center for Disease Control and prevention Retrieved October, 20, 2010, from http:// www.kcdchome/jsp/home/common/brd/COMMBRD0200Detail.jsp?m enuid=100049\&boardid=1012\&pageNum $=0 \&$ sub $=0 \&$ boardseq $=20915$

Elardo, R., \& Bradley, R. H. (1981). The home observation for measurement of the environment (HOME) scale: A review of research. Developmental Review, 1, 113-145.

Gale, C. R., O'Callaghan, F. J., Godfrey, K. M., Law, C. M., \& Martyn, C. N. (2004). Critical periods of brain growth and cognitive function in children. Brain, 127, 321-329.

Helfer, R. (1987). An overview of prevention. In: R. E. Helfer \& R. S. Kempe
(Eds.), The battered child (4th ed., pp. 425-433). Chicago: The University of Chicago Press.

Hong, M., \& Kim, H. J. (2007). Child abuse and neglect: Current situation and policy measures. Health and Welfare Policy Forum, 128, 47-59.

Ivanovic, D. M., Leiva, B. P., Perez, H. T., Olivares, M. G., Diaz, N. S., Urrutia, M. S. C., et al. (2004). Head size and intelligence, learning, nutritional status and brain development. Neuropsychologia, 42, 1118-1131.

Karp, R., Martin, R., Sewell, T., Manni, J., \& Heller, A. (1992). Growth and academic achievement in inner-city kindergarten children. Clinical Pediatrics, 31, 336-340.

McDonald, K. C. (2007). Child abuse: Approach and management. American Family Physician, 75, 221-228.

Mullen, P. E., Martin, J. L., Anderson, J. C., Romans, S. E., \& Herbison, G. P. (1996). The long-term impact of the physical, emotional and sexual abuse of children: A community study. Child Abuse \& Neglect, 20, 7-21.

Murry, S. K., Baker, A. W., \& Lewin, L. (2000). Screening families with young children for child maltreatment potential. Pediatric Nursing, 26, 47-54.

National Child Protection Agency. (2007). 2006 National Report on Child Abuse. KOREA Ministry of Health \& Welfare Retrieved October, 20, 2010, from http://www.bokjitimes.com/library/gov_pub/view.php?idxn $\mathrm{O}=98 \&$ menuno $=3 \&$ pageno $=1 \&$ menuno $=3 \& \mathrm{q}=\% \mathrm{BE} \% \mathrm{C} 6 \% \mathrm{~B} 5 \% \mathrm{BF} \% \mathrm{C} 7 \%$ D0\%B4\%EB\&qfield=TITLE\&ordertype=\&orderfield=

National Child Protection Agency. (2010). 2009 National Report on Child Abuse (Ministry of Health \& Welfare Publication No. 11-1352000-00002510). Seoul, Korea: Government Printing Office.

Olds, D. L., Eckenrode, J., Henderson, C. R. Jr., Kitzman, J., Powers, J., Cole, R., et al. (1997). Long-term effects of home visitation on maternal life course and child abuse and neglect. Fifteen-year follow-up of a randomized trial. Journal of the American Medical Association, 278, 637-643.

Park, M. S. (2002). Multidisciplinary collaboration in child protective services. Korean Journal of Child Studies, 13, 27-52.

Perepletchikova, F., \& Kaufman, J. (2010). Emotional and behavioral sequelae of childhood maltreatment. Current Opinion in Pediatrics, 22, 610-615.

Weich, S., Patterson, J., Shaw, R., \& Stewart-Brown, S. (2009). Family relationships in childhood and common psychiatric disorders in later life: Systematic review of prospective studies. The British Journal of Psychiatry, 194, 392-398.

Zielinski, D. S., Eckenrode, J., \& Olds, D. L. (2009). Nurse home visitation and the prevention of child maltreatment: Impact on the timing of official reports. Development and Psychopathology, 21, 441-453. 